\title{
RADIOCARBON/TREE-RING CALIBRATION, SOLAR ACTIVITY, AND UPWELLING OF OCEAN WATER
}

\author{
F B Knox \\ 900 Ohariu Valley Road, R.D., Johnsonville, Wellington, New Zealand. Email: fbmoknox@actrix.gen.nz. \\ B G McFadgen \\ Stout Research Centre for NZ Studies, Victoria University of Wellington, P.O. Box 600, Wellington, New Zealand. \\ Present address: 99 Sefton Street, Wellington, New Zealand. Email: mcfadgen@actrix.gen.nz.
}

\begin{abstract}
Least-squares fitted smooth curves to radiocarbon versus tree-ring calibration data for the period AD 1140 to 1950 are compared with climatic warming and cooling of the North Atlantic (Little Ice Age), and with recorded sunspot numbers over the period AD 1670 to 1950.

Calibration curves from different parts of the globe are not identical, and appear to be determined by a combination of variable solar activity and variable oceanic upwelling of ${ }^{14} \mathrm{C}$-depleted water, with the variable upwelling itself partly determined by solar activity.
\end{abstract}

\section{INTRODUCTION}

An optimum smoothing procedure for radiocarbon versus tree-ring age calibration curves (Knox and McFadgen 2001) showed calibration curves from different parts of the globe to be significantly different. Two extreme curves are from western North America (part of the INTCAL98 curve) and curves from New Zealand (Figure 1). Standard deviations for the smoothed curves are better than $10 \mathrm{yr}$ and calendar time resolutions are about $20 \mathrm{yr}$ for the later curves, and 27 and $45 \mathrm{yr}$ for the earlier curves. The average difference between the curves agrees with the recommended 24-yr adjustment between Northern and Southern Hemispheres (Stuiver et al. 1998), but the difference actually varies with time from 0 to $70 \mathrm{yr}$. In addition, there is a time variable longitudinal difference between the British Isles and western North America of up to $60 \mathrm{yr}$.

If only the typical \pm 50 -yr accuracy in individual measurements is wanted, then one universal calibration curve may be sufficient. Considering the accuracy now available from the tree-ring calibration viz. standard deviations better than $10 \mathrm{yr}$, there is a family of regional curves to be defined. What is needed to construct the family of regional curves is a set of calibration measurements spread across the globe, together with appropriate interpolation procedures. In order to achieve this, it is necessary to know what factors contribute to the wiggles in the calibration curves.

The purpose of this paper is to explore quantitatively the contribution from the 2 most likely factors: solar activity and upwelling to the sea surface of ${ }^{14} \mathrm{C}$-depleted water.

\section{CORRELATION OF ${ }^{14} \mathrm{C} / \mathrm{C}$ WITH SUNSPOT NUMBER AND CLIMATIC VARIATION}

Climatic cooling and warming in the North Atlantic is generally considered to correlate with variation in solar activity, but this is only really known for the Maunder and Dalton periods; prior to the Maunder period, there are no consistently reliable records of sunspot numbers (Royal Greenwich Observatory and SIDC data, in references). It is generally inferred (e.g. Damon et al. 1998) that the Wolf and Sporer periods correlate with solar activity from the observation that the corresponding climatic cooling correlates with the ${ }^{14} \mathrm{C}$ calibration curves in the same way as the Maunder and Dalton periods (Figure 2). Other observations (Damon et al. 1998; Rigozo et al. 2001) support the inference, which we consider valid, but, as we show, the correlation of ${ }^{14} \mathrm{C} / \mathrm{C}$ with solar activity is not altogether simple.

(C) 2004 by the Arizona Board of Regents on behalf of the University of Arizona Proceedings of the 18th International Radiocarbon Conference, edited by N Beavan Athfield and R J Sparks RADIOCARBON, Vol 46, Nr 2, 2004, p 987-995 


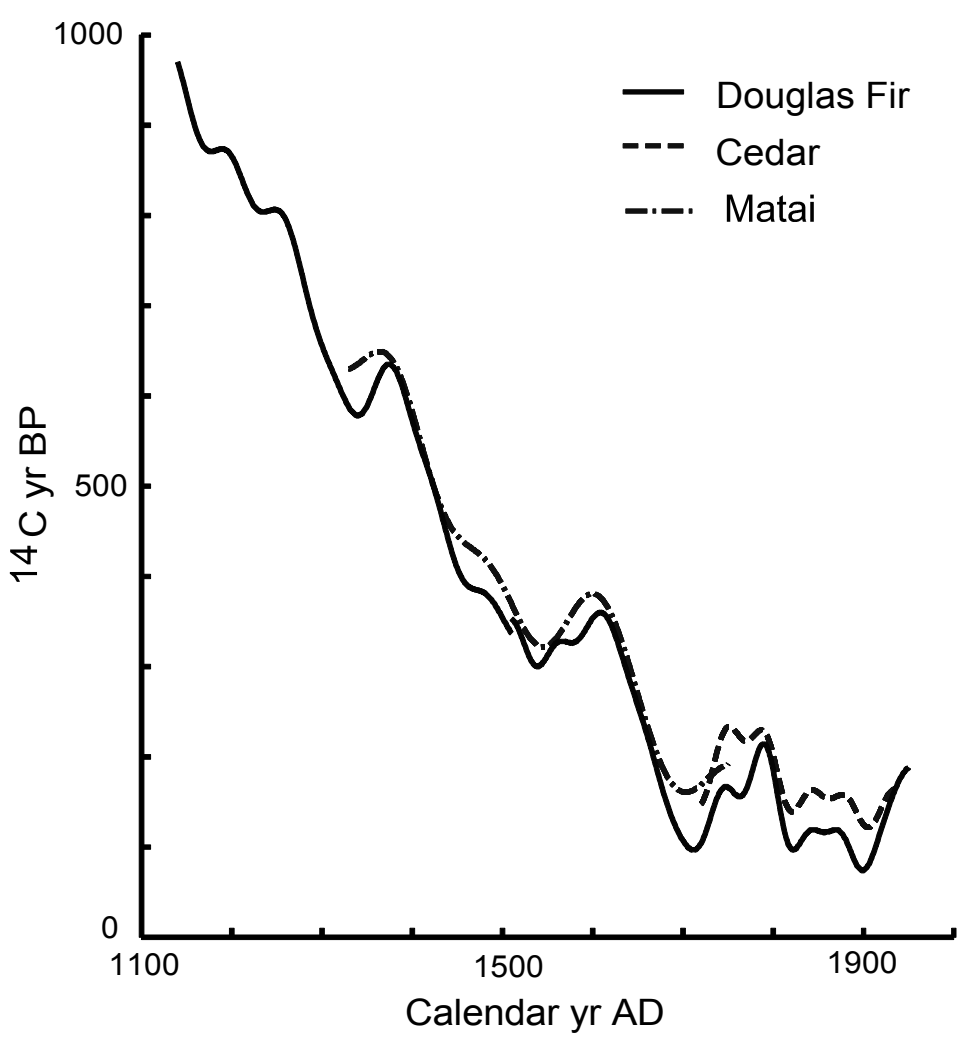

Figure 1 Smoothed calibration curves from the west coast of North America (Douglas fir) and New Zealand (cedar and matai). Standard deviation of early Douglas fir $=8 \mathrm{yr}$, late Douglas fir $=3 \mathrm{yr}$, cedar $=8 \mathrm{yr}$, matai $=9 \mathrm{yr}$.

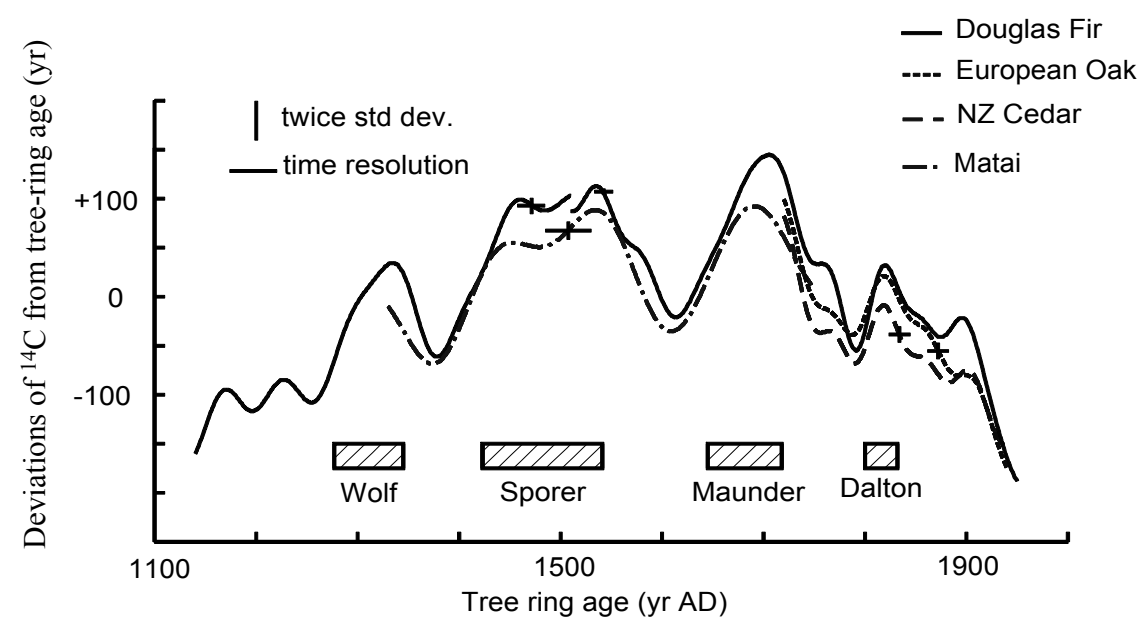

Figure 2 Detrended calibration curves from the west coast of North America (Douglas fir), British Isles (European oak), and New Zealand (cedar) compared with the Wolf, Sporer, Maunder, and Dalton periods of climatic cooling in the North Atlantic (Masarik and Beer 1999; Damon et al. 1998). The calibration curves have been detrended by taking the difference between ${ }^{14} \mathrm{C}$ and tree-ring age, and plotting the difference as deviations of ${ }^{14} \mathrm{C}$ from tree-ring age. 
The decadal ${ }^{14} \mathrm{C}$ curves used below all have calendar resolution times close to $20 \mathrm{yr}$; so to facilitate comparison (Figure 3), the sunspot curve has been decadally averaged and then smoothed with a 5point binomial digital filter (a weighted running mean with weighting ratios 1:4:6:4:1). This filter applied to decadal data can be shown to give a resolution time close to $20 \mathrm{yr}$; due to this, the 11-yr cycle does not appear. Sunspot numbers were first reliably and consistently recorded only after AD 1700 (Royal Greenwich Observatory and SIDC data, in references). Prior to AD 1700, well into the Maunder Minimum, we take the sunspot number as zero (Figure 3). Prior to AD 1850, Figure 3 shows that time variation of the ${ }^{14} \mathrm{C} / \mathrm{C}$ ratio in all 3 calibration curves lags the sunspot variation. The section "Analysis of Calibration Sites" discusses a possible reason for this.
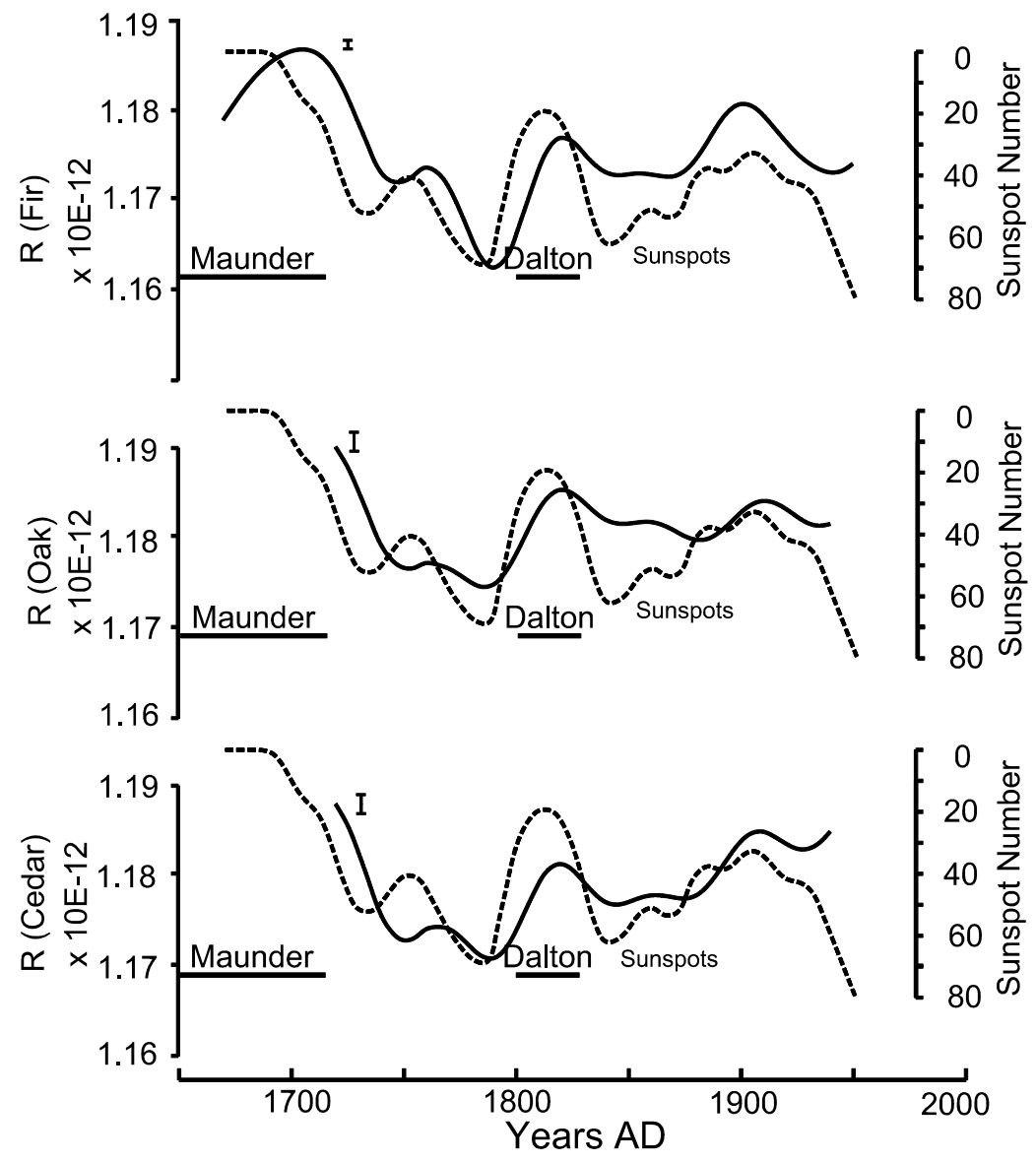

Figure 3 Sunspot number (averaged and smoothed) versus time, compared with the ${ }^{14} \mathrm{C} / \mathrm{C}$ ratios $(\mathrm{R})$ in fir (western North America), oak (British Isles), and cedar (New Zealand) calibration curves. The curves are approximately corrected for the Suess effect (see text). From AD 1700 onwards, sunspot data was obtained from the web site references. Error bar range is twice standard deviation.

\section{QUANTITATIVE ANALYSIS}

To analyze the situation quantitatively, we start by modifying an equation used by Lassey et al. (1990) for the rate of change of the global ${ }^{14} \mathrm{C}$ inventory, ${ }^{14} \mathrm{I}$ : 


$$
(\mathrm{d} / \mathrm{dt})^{14} \mathrm{I}=\mathrm{Q}-\mathrm{k}\left(1-\mathrm{R}_{\mathrm{m}} / \mathrm{R}\right){ }^{14} \mathrm{I}-\lambda^{14} \mathrm{I}
$$

where $Q$ is the cosmogenic production rate of ${ }^{14} \mathrm{C}$, the radioactive decay rate $\lambda=1 /(8267 \mathrm{yr})$, and $k=1 /\left[7.2 \times(0.975)^{2} \mathrm{yr}\right]$ is the exchange rate coefficient for the net carbon flux from atmosphere to ocean surface adjusted for fractionation to the mean surface ocean value of $\delta^{13} \mathrm{C}=0$. The variables $\mathrm{R}_{\mathrm{m}}$ and $\mathrm{R}$ are the ${ }^{14} \mathrm{C} / \mathrm{C}$ ratios in the upper mixed layer of the ocean and the atmosphere, respectively, corrected for fractionation to $\delta^{13} \mathrm{C}=-25 \%$.

Let I be the global total carbon inventory for the atmosphere, then $\mathrm{R}$ is ${ }^{14} \mathrm{I} / \mathrm{I}$, and

$$
(\mathrm{d} / \mathrm{dt}){ }^{14} \mathrm{I}=(\mathrm{d} / \mathrm{dt})(\mathrm{R} \mathrm{I})=(\mathrm{dR} / \mathrm{dt}) \mathrm{I}+\mathrm{R}(\mathrm{dI} / \mathrm{dt})
$$

Inserting equation (2) into equation (1) and dividing through by I gives

$$
\mathrm{dR} / \mathrm{dt}=\mathrm{Q} / \mathrm{I}-(\mathrm{k}+\lambda+\sigma) \mathrm{R}+\mathrm{k} \mathrm{R}_{\mathrm{m}}
$$

where $\sigma$ is $(\mathrm{dI} / \mathrm{dt}) / \mathrm{I}$.

A best estimate of the ${ }^{14} \mathrm{C}$ production rate per unit area in the stratosphere as a function of sunspot number is taken from Lal (1992: Equation 3) with the variable term increased by 20\% (see Lal 1992, section 4). This rate is multiplied by the area of the earth at stratospheric height (equivalent radius $6380 \mathrm{~km}$ ) and divided by the total carbon inventory to give $\mathrm{Q} / \mathrm{I}=\alpha-\beta \mathrm{S}$, where $\alpha=4.2 \times 10^{26}$ atom $\mathrm{yr}^{-1} / \mathrm{I}$ and $\beta=1.1 \times 10^{24}$ atom $\mathrm{yr}^{-1} / \mathrm{I}$ and $\mathrm{S}$ is the sunspot number. Equation (3) can now be written as

$$
(\mathrm{d} / \mathrm{dt}) \mathrm{R}=\alpha-\beta \mathrm{S}-(\mathrm{k}+\lambda+\sigma) \mathrm{R}+\mathrm{k} \mathrm{R}_{\mathrm{m}}
$$

Next, consider the rate of change of ${ }^{14} \mathrm{C} / \mathrm{C}$ in the upper mixed layer of the ocean:

$$
(\mathrm{d} / \mathrm{dt}){ }^{14} \mathrm{I}_{\mathrm{m}}=\mathrm{k}\left(1-\mathrm{R}_{\mathrm{m}} / \mathrm{R}\right){ }^{14} \mathrm{I}-\lambda^{14} \mathrm{I}_{\mathrm{m}}+\mathrm{k}_{\mathrm{d}}\left({ }^{14} \mathrm{I}_{\mathrm{d}}-{ }^{14} \mathrm{I}_{\mathrm{m}}\right)
$$

The term $\mathrm{k}\left(1-\mathrm{R}_{\mathrm{m}} / \mathrm{R}\right){ }^{14} \mathrm{I}$, which in equation (1) is the net flux of ${ }^{14} \mathrm{C}$ from the atmosphere to the ocean, becomes in equation (5) the production rate for the ocean. The term $\mathrm{k}_{\mathrm{d}}\left({ }^{14} \mathrm{I}_{\mathrm{d}}-{ }^{14} \mathrm{I}_{\mathrm{m}}\right)$ represents an unknown depletion rate of ${ }^{14} \mathrm{C}$ due to upwelling of ocean water: ${ }^{14} \mathrm{I}_{\mathrm{d}}$ being the global total ${ }^{14} \mathrm{C}$ inventory of depleted ocean water rising and mixing into the surface layer, and $\mathrm{k}_{\mathrm{d}}$ an unknown constant.

Proceeding as before,

$$
(d / d t){ }^{14} I_{m}=(d / d t)\left(R_{m} I_{m}\right)=\left(d R_{m} / d t\right) I_{m}+R_{m}\left(d I_{m} / d t\right)
$$

and inserting equation (6) into equation (5) and dividing through by $\mathrm{I}_{\mathrm{m}}$ gives

$$
\mathrm{dR}_{\mathrm{m}} / \mathrm{dt}=\mathrm{kXR}-\left(\mathrm{kX}+\lambda+\sigma_{\mathrm{m}}\right) \mathrm{R}_{\mathrm{m}}+\mathrm{U}
$$

where $\mathrm{I}_{\mathrm{m}}$ is the global total $\mathrm{C}$ inventory in the upper mixed layer of the ocean, $\mathrm{X}=\mathrm{I} / \mathrm{I}_{\mathrm{m}}, \sigma_{\mathrm{m}}=\left(\mathrm{dI}_{\mathrm{m}} /\right.$ $\mathrm{dt}) / \mathrm{I}_{\mathrm{m}}$ and $\mathrm{U}=\mathrm{k}_{\mathrm{d}}\left({ }^{14} \mathrm{I}_{\mathrm{d}}-{ }^{14} \mathrm{I}_{\mathrm{m}}\right) / \mathrm{I}_{\mathrm{m}}$, the rate of change of ${ }^{14} \mathrm{C} / \mathrm{C}$ in surface sea water due to upwelling.

Measurements of $R_{m}$ are not always available in the vicinity of any given calibration tree, but $R_{m}$ can be eliminated from the calculation. To do this, differentiate equation (4) with respect to time to get

$$
\mathrm{d}^{2} \mathrm{R} / \mathrm{dt}^{2}=-\beta(\mathrm{dS} / \mathrm{dt})-(\mathrm{d} \beta / \mathrm{dt}) \mathrm{S}-(\mathrm{k}+\lambda+\sigma)(\mathrm{dR} / \mathrm{dt})-(\mathrm{d} \sigma / \mathrm{dt}) \mathrm{R}+\mathrm{k}\left(\mathrm{dR} \mathrm{m}_{\mathrm{m}} / \mathrm{dt}\right)
$$


and substitute $d R_{m} / d t$ from equation (8), and $R_{m}$ from equation (4) into equation (7). After rearranging by putting the external driving terms, $\mathrm{U}$ and the solar activity terms, on one side of the equation as a driving function, $\mathrm{V}$, this yields

$$
\mathrm{U}+\mathrm{C}_{\mathrm{S}}(\alpha-\beta \mathrm{S})+[(\mathrm{d} / \mathrm{dt})(\alpha-\beta \mathrm{S})] / \mathrm{k}=\mathrm{V}=\mathrm{C}_{0} \lambda \mathrm{R}+\mathrm{C}_{1}(\mathrm{dR} / \mathrm{dt})+\left(\mathrm{d}^{2} \mathrm{R} / \mathrm{dt}^{2}\right) / \mathrm{k}
$$

where

$$
\begin{gathered}
\left.\mathrm{C}_{0}=\mathrm{X}(1+\sigma / \lambda)+[1+(\lambda+\sigma) / \mathrm{k})\right]\left(1+\sigma_{\mathrm{m}} / \lambda\right)+(\mathrm{d} \sigma / \mathrm{dt}) /(\mathrm{k} \lambda), \\
\mathrm{C}_{1}=1+\mathrm{X}+\left(2 \lambda+\sigma+\sigma_{\mathrm{m}}\right) / \mathrm{k}, \text { and } \mathrm{C}_{\mathrm{S}}=\mathrm{X}+\left(\lambda+\sigma_{\mathrm{m}}\right) / \mathrm{k} .
\end{gathered}
$$

The above equates the driving function with an expression derived from ${ }^{14} \mathrm{C}$ measurements made entirely in the calibration wood. $\mathrm{V}$ expresses the combined effects of variable ocean upwelling and variable ${ }^{14} \mathrm{C} / \mathrm{C}$ production in the stratosphere, driving the change of ${ }^{14} \mathrm{C} / \mathrm{C}$ in the troposphere.

The right-hand side of equation (9) is the sum of 3 terms proportional to $\mathrm{R}$ (the measured ${ }^{14} \mathrm{C} / \mathrm{C}$ ratio), to $\mathrm{dR} / \mathrm{dt}$ (the slope) and to $\mathrm{d}^{2} \mathrm{R} / \mathrm{dt}^{2}$ (the curvature of $\mathrm{R}$ ), respectively, when plotted against calendar time, and it is this combination which fully measures the combined effects on $\mathrm{R}$ of upwelling and variable ${ }^{14} \mathrm{C}$ production.

\section{ANALYSIS OF CALIBRATION SITES}

A significant amount of the reduction of the ${ }^{14} \mathrm{C} / \mathrm{C}$ ratio after about $\mathrm{AD} 1750$ is due to human activity (the Suess effect) (Figure 2). In Figure 3 and subsequent figures, this has been approximately corrected for by letting I, the total carbon inventory, increase exponentially from its value at AD 1750 to $3 \%$ more than this value at $\mathrm{AD} 1950$ (Lassey et al. 1990). For this exploratory analysis I, before $\mathrm{AD} 1750$, is assumed to be constant at $3.02 \times 10^{40}$ atom (Lassey et al. 1996), but a more thorough analysis would also look at the effect of a more generally variable I.

Comparison of $\Delta \mathrm{V}$, the variation of $\mathrm{V}$ about the local average for the fir $\left(1.6 \times 10^{-16} / \mathrm{yr}\right)$, oak $\left(1.8 \times 10^{-16} / \mathrm{yr}\right)$, and cedar $\left(2.4 \times 10^{-16} / \mathrm{yr}\right)$ is given in Figure 4. The standard deviations for the $\Delta \mathrm{V}$ are $0.6 \times 10^{-16} / \mathrm{yr}$ for the fir, and $1.6 \times 10^{-16} / \mathrm{yr}$ for both the oak and the cedar. A resolution time of $20 \mathrm{yr}$ over the interval AD 1720 to 1940 is equivalent to the curves being plotted through 11 independent points. $\chi^{2}$ tests for significance of the differences between the curves show the differences between fir and oak and between fir and cedar to be highly significant, but the difference between oak and cedar to be not significant (Snedecor and Cochran 1967).

With 11 degrees of freedom (11 independent points), the correlation coefficients for fir and oak (0.83), fir and cedar (0.86), and oak and cedar (0.96) are all individually highly significant (Snedecor and Cochran: §7.6), but the differences between the correlation coefficients are not significant (Snedecor and Cochran: §7.7 and §2.13).

The above and Figure 4 together show that between all 3 sites the variation of $\mathrm{V}$ is highly correlated, but that the amplitude of the variation for the North American west coast is significantly greater than the amplitudes for either the British Isles or New Zealand. Amplitudes for the British Isles and New Zealand do not differ significantly. This difference may relate to stronger upwelling of water along the North American west coast. More ${ }^{14} \mathrm{C} / \mathrm{C}$ depletion has been measured in surface water off the North American west coast than in such water in the immediate vicinity of New Zealand or the British Isles (Stuiver and Braziunas 1993). 

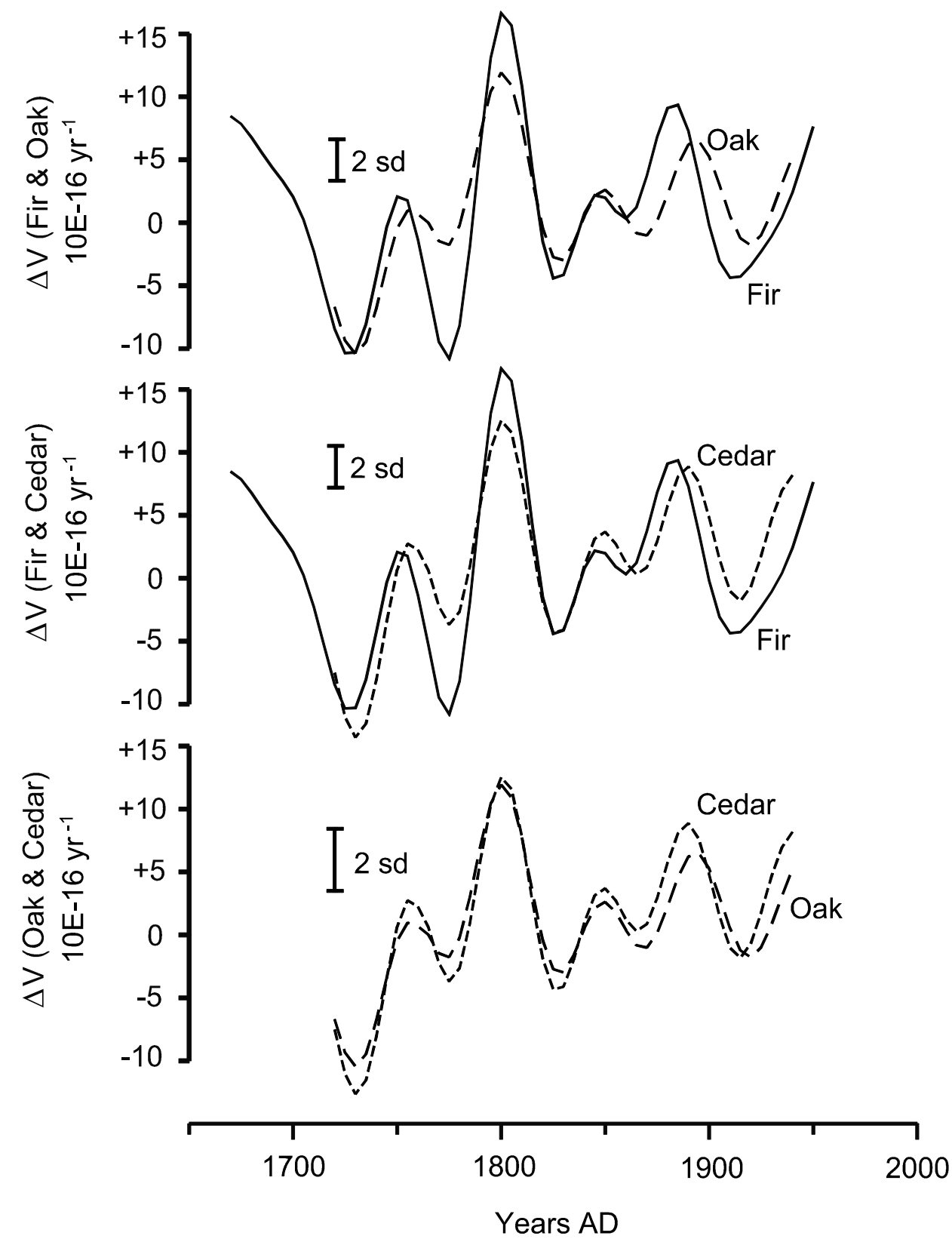

Figure 4 Comparisons of $\Delta \mathrm{V}\left(\mathrm{yr}^{-1}\right)$ obtained entirely from tree calibration data for the 3 calibration sites versus time.

There is increasing evidence for correlation of climate with solar activity (Foukal 2003), and we must make allowance for the possibility that solar activity may affect upwelling ${ }^{2}{ }^{14} \mathrm{C}$-depleted water, through variable heating of the upper layer of the ocean. To examine this, we estimate a quantity $\Delta \mathrm{T}$, which is proportional to the solar activity induced fluctuation of sea surface temperature about its average temperature. We then compare at the 3 calibration sites, $\Delta \mathrm{T}$ with the rate of reduction of ${ }^{14} \mathrm{C} / \mathrm{C}$ in surface seawater due to upwelling (U) (Figure 5). However, it should be pointed out 
that, within existing climate models, the variation of solar heat output found over 2 solar cycles seems to be too small, by a factor of 3 to 5 , to account for the correlation (Foukal 2003). We will look at this again later.

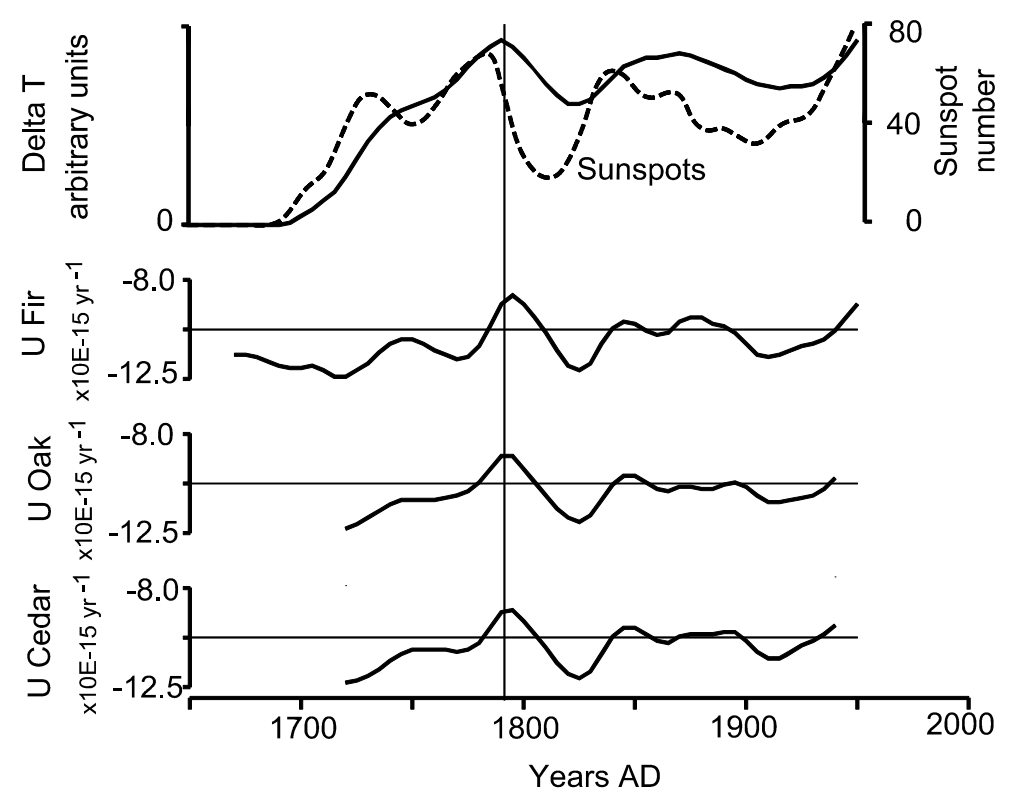

Figure $5 \Delta \mathrm{T}$ (for $\tau=30 \mathrm{yr}$ ), smoothed sunspot number, and $\mathrm{U}\left(\mathrm{yr}^{-1}\right)$ for the 3 calibration sites versus time.

Since the variation in solar heat output is small compared with the average output, then considering the uncertainties, an assumed linear form for the variation of heat output as a function of sunspot number is all that is warranted at this stage. At least it should be more comparable with $U$ than unprocessed sunspot numbers. The underlying assumption is that variable heating, through changing buoyancy of the upper sea surface layer, modulates the effective area of spread of previously deeper cooler ocean water over the surface, where it exchanges ${ }^{14} \mathrm{C}$ directly with the atmosphere.

$\Delta \mathrm{T}$, the fluctuation of sea surface temperature about the average temperature, is given by:

$$
(\mathrm{d} / \mathrm{dt}) \Delta \mathrm{T}=\text { (constant) } \mathrm{S}(\mathrm{t})-(\text { constant }) \Delta \mathrm{T}
$$

where the first term on the right-hand side of equation (10) is the variable heat input to the ocean (assumed proportional to sunspot number), and the second term is the excess heat loss from the surface layer (assumed proportional to $\Delta \mathrm{T}$ ). The solution to this differential equation yields

$$
\Delta T \propto \exp (-t / \tau) \int S(t) \exp (t / \tau) d t
$$

where $\tau$ is a time constant related to how fast excess heat is lost from the surface layer.

$\Delta \mathrm{T}$, for $\tau=30 \mathrm{yr}$, is plotted against $\mathrm{t}$ and compared with $\mathrm{U}$ at the 3 calibration sites in Figure 5. However, some of the terms contributing to $U$ (Equation 9) directly relate to sunspot number, so care is needed in interpreting any correlation of $\mathrm{U}$ with $\Delta \mathrm{T}$, a quantity derived directly from this number. In the extreme case, if $U$ was not correlated with solar activity the sunspot terms in equation (9) would 
all cancel with parts of the calibration tree terms. But if, for example, the expression used for the variation of ${ }^{14} \mathrm{C}$ production with sunspot number was significantly in error, the cancelling would not be exact and a spurious correlation of $\mathrm{U}$ with $\Delta \mathrm{T}$ would emerge.

While it cannot be ruled out that the observed correlation of $\mathrm{U}$ with $\Delta \mathrm{T}$ is spurious, it cannot be entirely so. The correlation makes physical sense. In Figure 5, increasing $\Delta \mathrm{T}$ leading to increasing buoyancy of the upper surface layer correlates with a decreasing magnitude of $U$, as the amount of depleted water brought up to and spread out over the sea surface declines.

In Figure 5, the curve $\Delta \mathrm{T}$ versus $\mathrm{t}$, for finite $\tau(>0)$, is smoother than $\mathrm{S}$ versus $\mathrm{t}$ and is delayed in time. Putting $\tau=30$ yr yields a $\Delta \mathrm{T}$ delayed by $9 \mathrm{yr}$, which synchronizes well with the $\mathrm{U}$. The matching delay in the $U$ cannot be spurious, since no such delay applied to $\mathrm{S}$ occurs in equation (9).

The curve $\Delta \mathrm{T}$ versus $\mathrm{t}$ is also smoother than the $\mathrm{U}$ curves, and since the $\mathrm{U}$ are supposed to correlate directly only with $\Delta \mathrm{T}$ (not $\mathrm{S}$ ), it could be construed that the enhanced variation in the $\mathrm{U}$ is spurious, but another explanation is possible. If the warmer buoyant sea surface layer has one or more natural oscillatory periods in its motion of covering and uncovering the cooler upwelled water, it may respond to the variable heating as a set of damped harmonic oscillators (Jaeger 1951).

If some external force, in this case the excess buoyancy, induces motion in the layer, the motion will be dominated by broad resonance between the natural periods of the layer and nearby periods in the external force. Thus, the enhanced variation in the $\mathrm{U}$ compared with $\Delta \mathrm{T}$ may be due to resonance with the corresponding muted variation in $\Delta \mathrm{T}$, extending back over a long time (to well before the Maunder Minimum) to allow build-up of the resonance.

It is also possible that the periods involved in the resonance will be less than the resolving time (20 yr) of the present smoothed data. In this case, the resonant build-up time could be shorter, with the time variation visible in the figures being some function of a longer-term modulation of the shorter period oscillations.

Resonance between variable upwelling (proportional to $\mathrm{U}$ ) and variable heating may also be responsible for the previously mentioned enhancement by a factor of 3 to 5 needed in existing climate models to account for the correlation of climate with (so far observed) heating associated with solar activity (Foukal 2003).

\section{CONCLUSION}

The reason for ${ }^{14} \mathrm{C}$ versus tree-ring calibration curves from different parts of the globe not being identical appears to be mainly due to exchange of $\mathrm{CO}_{2}$ between the atmosphere and seawater in which the ${ }^{14} \mathrm{C} / \mathrm{C}$ ratio is variable. Mixing of variable proportions of upwelled ${ }^{14} \mathrm{C}$-depleted ocean water into the surface ocean layer brings about variability in the surface layer. Variable solar heating related to solar activity appears to modulate the mixing. The variability brought about by exchange of $\mathrm{CO}_{2}$ with surface seawater, combined with the variable ${ }^{14} \mathrm{C}$ production in the stratosphere due to changes in solar activity, leads to a complicated, but calculable, correlation of the tropospheric ${ }^{14} \mathrm{C} / \mathrm{C}$ ratio with sunspot number.

The exploratory analysis in this paper has been carried out on only 3 sites, albeit widely spaced across the globe, but they are all mid-latitude, essentially oceanic sites. A more thorough analysis is required using, in addition, data from low and high latitudes and from inland sites. It would be desirable to extend the analysis back in time beyond the beginning of the Maunder Minimum, if a reliable proxy (other than sunspot number) for solar activity is developed. If this can be achieved, and with 
the added advantage of historical accounts, the last $1000 \mathrm{yr}$ of ${ }^{14} \mathrm{C}$ versus tree-ring calibration data, from the medieval maximum through the periods of climatic cooling to the modern maximum, represents a unique opportunity to develop insight into variable solar heating and climate change.

The above would also allow the development of a global family of calibration curves that takes account of spatial as well as temporal variation.

Finally, although $R_{m}$ in this paper is eliminated between equations (4) and (7), these equations can be differently combined (or kept separate) to make explicit use of $R_{m}$ as desired.

\section{ACKNOWLEDGEMENTS}

For discussions and help, we thank Dr B Carter of the Carter Observatory; Drs W Allan, L Carter, D Lowe, K Lassey, and P Sutton of the National Institute of Water and Atmospheric Research; and Dr R Sparks of the Rafter Radiation Laboratory, Institute of Geological and Nuclear Sciences: Wellington, New Zealand.

\section{REFERENCES}

Damon PE, Eastoe CJ, Hughes MK, Kalin RM, Long A, Peristykh AN. 1998. Secular variation of $\Delta{ }^{14} \mathrm{C}$ during the medieval solar maximum: a progress report. Radiocarbon 40(1):343-50.

Foukal P. 2003. Can slow variations in solar luminosity provide missing link between the sun and climate. Eos, Transactions, American Geophysical Union 84(22):205, 208

Jaeger JC. 1951. An Introduction to Applied Mathematics. Oxford: Clarendon Press. §31:76-82.

Knox FB, McFadgen BG. 2001. Least-squares fitting smooth curves to decadal radiocarbon calibration data from AD 1145 to AD 1945. Radiocarbon 43(1):87118.

Lal D. 1992. Expected secular variations in the global terrestrial production rate of radiocarbon. NATO ASI Series 12:113-26.

Lassey K, Manning MR, O’Brien BJ. 1990. An overview of oceanic radiocarbon: its inventory and dynamics. Reviews in Aquatic Sciences 3(2\&3):117-46.

Lassey K, Enting IG, Trudinger CM. 1996. The earth's radiocarbon budget. Tellus 48B:487-501.

Masarik J, Beer J. 1999. Simulation of particle fluxes and cosmogenic nuclide production in the earth's atmo- sphere. Journal of Geophysical Research 104(D10): 12,099-111.

Royal Greenwich Observatory. Sunspot Record 18742004. Space Science Center (NASA). Solar Physics Data. The Sunspot Cycle. Monthly Averages. http:// science.msfc.nasa.gov/ssl/pad/solar/greenwch_spot_ num.txt.

Rigozo NR, Echer E, Vieira LEA, Nordemann DJR. 2001. Reconstruction of Wolf sunspot numbers on the basis of spectral characteristics and estimates of associated radio flux and solar wind parameters for the last millennium. Solar Physics 203:179-91.

Solar Influences Data Analysis Center (SIDC). Royal Observatory of Belgium, Brussels, Belgium. Sunspot Archive. Yearly Sunspot Number. http://sidc.oma.be/ DATA/yearssn.dat.

Snedecor GW, Cochran WG. 1967. Statistical Methods. 6th edition. Ames: Iowa State University Press. 593 p.

Stuiver M, Braziunas TF. 1993. Modeling atmospheric ${ }^{14} \mathrm{C}$ influences and ${ }^{14} \mathrm{C}$ ages of marine samples to 10,000 BC. Radiocarbon 35(1):137-89.

Stuiver M, Reimer PJ, Braziunas TF. 1998. High-precision radiocarbon age calibration for terrestrial and marine samples. Radiocarbon 40(3):1127-51. 